\title{
Estimating population sizes of lions Panthera leo and spotted hyaenas Crocuta crocuta in Uganda's savannah parks, using lure count methods
}

\author{
Edward Oкот Omoya, Tutilo Mudumba, Stephen T. Buckland, Paul Mulondo \\ and ANDREW J. PLUMPTRE
}

\begin{abstract}
Despite $>60$ years of conservation in Uganda's national parks the populations of lions and spotted hyaenas in these areas have never been estimated using a census method. Estimates for some sites have been extrapolated to other protected areas and educated guesses have been made but there has been nothing more definitive. We used a lure count analysis method of call-up counts to estimate populations of the lion Panthera leo and spotted hyaena Crocuta crocuta in the parks where reasonable numbers of these species exist: Queen Elizabeth Protected Area, Murchison Falls Conservation Area and Kidepo Valley National Park. We estimated a total of 408 lions and 324 hyaenas for these three conservation areas. It is unlikely that other conservation areas in Uganda host $>10$ lions or $>40$ hyaenas. The Queen Elizabeth Protected Area had the largest populations of lions and hyaenas: 140 and 211, respectively. It is estimated that lion numbers have declined by $30 \%$ in this protected area since the late 1990 s and there are increasing concerns for the long-term viability of both species in Uganda.
\end{abstract}

Keywords Call-up census, hyaenas, lions, lure count, population estimation, Uganda

\section{Introduction}

Curveys are essential to detect significant threats to $\checkmark$ wildlife or substantial declines in abundance (Treves et al., 2009). However, estimating numbers of large carnivores is difficult because they occur at low density, are usually cryptic and are often nocturnal. In areas where aerial surveys are feasible it is sometimes possible to estimate prey biomass density, which is often correlated with large carnivore density (Treves et al., 2009), to give the carrying capacity for large carnivores, assuming no anthropogenic factors are involved (Kiffner et al., 2009). Lions Panthera leo and some of their prey are undercounted by aerial surveys

Edward Okot Omoya, Tutilo Mudumba, Paul Mulondo and Andrew J. Plumptre (Corresponding author) Wildlife Conservation Society, Albertine Rift Programme, Plot 802, Kiwafu Road, Kansanga, P.O. Box 7487, Kampala, Uganda. E-mail aplumptre@wcs.org

STEPHEN T. BUCKLAND School of Mathematics and Statistics, University of St Andrews, Scotland

Received 12 October 2012. Revision requested 20 November 2012. Accepted 9 January 2013. First published online 24 October 2013. but the medium-to-large ungulates of open country that constitute the major prey of lions are usually estimated with reasonable accuracy (Schaller, 1972; Hunter, 1998; Hayward \& Kerley, 2005), making prey counts an attractive option. Developing consistent and reliable methods for estimating population density is pivotal for many studies in animal ecology as well as for efficient population assessment and allocation of conservation effort (Dacier et al., 2011).

Survey methods developed to estimate the population density of African lions include roar counts, individual identification, and mark-recapture methods (Ogutu \& Dublin, 1998; IUCN, 2007). These methods are usually timeconsuming and therefore expensive to undertake; as a result they are usually applied to only one protected area or a study site within a protected area.

Mills (1985) counted spotted hyaenas Crocuta crocuta (henceforth referred to as hyaenas) by broadcasting animal vocalizations to call in the target species. This technique generates reliable estimates for both hyaenas and lions provided it is accurately calibrated (Ogutu \& Dublin, 1998). The calibration procedure involves a systematic assessment of factors that influence variability in carnivore response to the broadcast call and the reliability of density estimates obtained compared with independent estimates of known accuracy. Response is defined as the intentional movement of animals previously engaged in some activity, such as resting, to within the observer's field of view, solely as a result of exposure to broadcast calls. Methods have been developed to analyse these lure counts, using a response curve to a broadcast call or attractant to calculate the density of a species (Buckland et al., 2006). These methods change the way call-up data are analysed by calculating the decline in response of an animal with distance from the call-up station. Previous studies have taken the maximum distance at which an animal responds as the call-up distance but have presented data showing that not all animals tested near this maximum distance responded (Ogutu \& Dublin, 1998; Ferreira \& Funston, 2010). Mills et al. (2001) tried to compensate for this decline in response with distance by calculating the percentage response of animals within the maximum distance but this percentage can change depending on the arbitrary selection of the maximum distance. Whitman et al. (2006) tried to model how response changes with distance from the station. The lure count analysis fits a curve through the data of responding animals with distance 


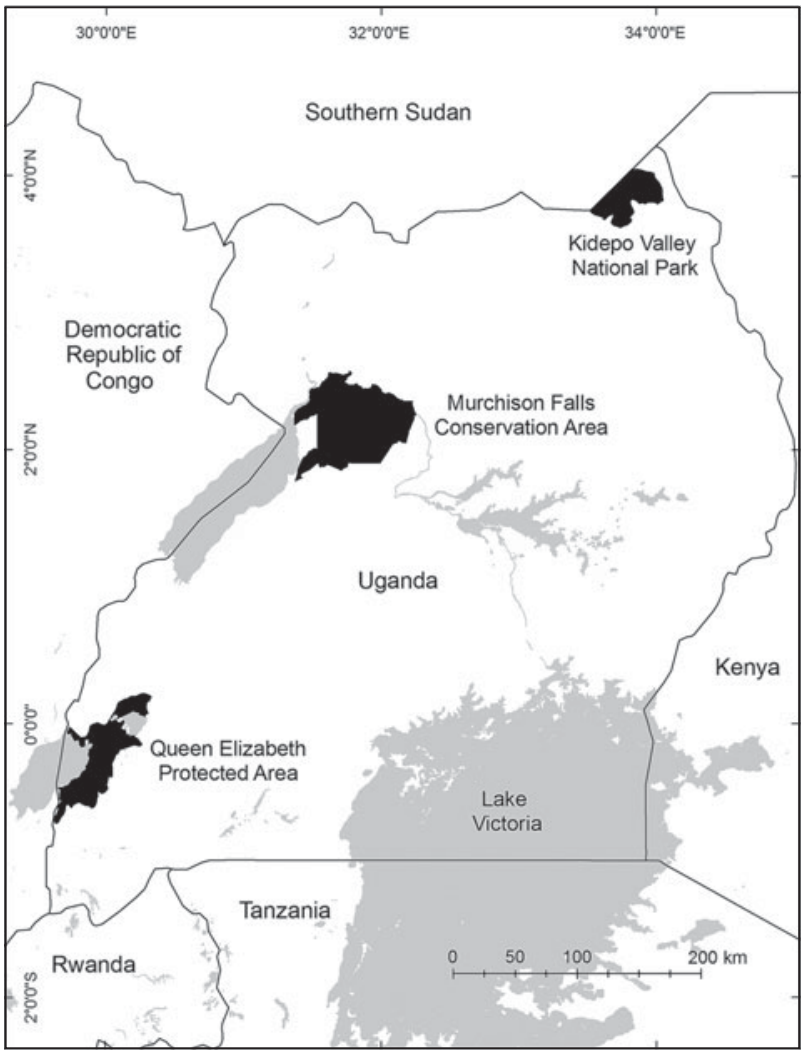

FIG. 1 Uganda, showing the location of the three conservation areas surveyed in this study.

from the call station and there is no need to define a maximum response distance as a result. It uses point transect sampling methods, in which the probability of detection is estimated as a function of distance from trials on animals at known locations. An effective radius of response is calculated, which estimates the distance at which the number of animals beyond the radius that respond is equal to the number closer to the lure that do not respond.

We describe the use of this lure count analysis on call-up data to estimate numbers of lions and spotted hyaenas in Uganda. We use the term 'lure count' to refer to the specific analysis method described by Buckland et al. (2006).

\section{Study area}

We estimated the density and distribution of lions and hyaenas in Uganda's three major savannah national parks: Kidepo Valley National Park, Murchison Falls Conservation Area and the Queen Elizabeth Protected Area, which comprises the Queen Elizabeth National Park and the adjoining wildlife reserves of Kigezi and Kyambura (Fig. 1). All of these conservation areas are managed by the Uganda Wildlife Authority. Lions also occur in Toro-Semliki Wildlife Reserve and occasionally in Lake Mburo National Park and Kabwoya Wildlife Reserve but numbers are very small.
The earliest sources of information on Uganda's lions are Din (1978) and Van Orsdol (1981), who estimated 400 lions in the Queen Elizabeth Protected Area. In subsequent studies Driciru et al. estimated 185 and 206 individuals in the same area (Driciru 1999, 2005; Driciru, Siefert \& Mapesa, 2005). The Uganda Large Predator Program (2000-2002) at Makerere University estimated 206 individuals, and Bauer \& Van Der Merwe (2004) estimated 200 individuals. These estimates were made by extrapolating densities from study sites to the rest of the Protected Area. Driciru et al. (1996), estimated that the total number of lions in Uganda was $345-745$. Such a wide range indicates the uncertainty of the species' status in the country in the 1990s.

Historically spotted hyaenas were widespread in Uganda (Mills \& Hofer, 1998) but now they rarely occur outside protected areas. They are known to occur in Queen Elizabeth, Murchison Falls, Lake Mburo, Kidepo Valley, Mgahinga Gorilla and Mt Elgon National Parks and in Kigezi, Kyambura, Bugungu, and Karuma wildlife reserves. According to the IUCN Action Plan for Hyaenas, Uganda is data deficient, implying that although the species is known to occur in the country, there is no information on its distribution and conservation status (Mills \& Hofer, 1998). Prior to our survey there was no published estimate of the hyaena population in Uganda.

\section{Methods}

\section{Lure count analysis method of call-up counts}

We used a lure count analysis method (Buckland et al., 2006) to estimate lion and hyaena numbers in the Queen Elizabeth Protected Area, Kidepo Valley National Park and Murchison Falls Conservation Area from call-up counts. The surveys were made between 29 November and 6 December 2008 in Queen Elizabeth, between 24 March and 1 April 2009 in Kidepo Valley, and between 6 September and 26 November 2009 in Murchison Falls. The locations of the call stations were determined by a randomly placed grid of points $5 \mathrm{~km}$ apart on a map of the three study areas, using ArcGIS v. 9.2 (ESRI, Redlands, USA). We visited the points between 09.00 and 16.00 to locate areas within $50 \mathrm{~m}$ of the call station with good accessibility and visibility for the subsequent night count. When selecting the call stations we omitted areas where hyaenas and lions do not occur, such as ranger settlements, rivers, dense tropical high forests and woodland (where rangers have not encountered lion or hyaena signs), lakes, and wetlands (percentage unsampled: Queen Elizabeth Protected Area, 42.3\%; Kidepo Valley National Park, 10.9\%; Murchison Falls Conservation Area, 20.6\%). Estimated densities were then extrapolated to the area of park where lions and hyaenas could occur, to estimate population sizes. During $19.00-01.00$ we drove to the 
TABLE 1 Total area of each of Uganda's three main strongholds for lions and hyaenas (Fig. 1), area of suitable habitat where call-up stations were established, and the percentage of this area sampled by the call-ups, based on the effective radius of the response. The effective radii of response are smaller than those used in previous counts where the maximum distance was used; therefore the percentage sampling effort is lower but more accurate.

\begin{tabular}{lllll}
\hline Site & Area $\left(\mathrm{km}^{2}\right)$ & $\begin{array}{l}\text { Area suitable for lions } \\
\text { or hyaenas }\left(\mathrm{km}^{2}\right)\end{array}$ & $\begin{array}{l}\text { Sampling effort } \\
\text { for lions }(\%)\end{array}$ & $\begin{array}{l}\text { Sampling effort } \\
\text { for hyaenas }(\%)\end{array}$ \\
\hline Queen Elizabeth Protected Area & 2,401 & 1,386 & 19.3 & 60.0 \\
Kidepo Valley National Park & 1,442 & 1,284 & 14.3 & 44.4 \\
Murchison Falls Conservation Area & 5,045 & 4,004 & 13.7 & 42.7 \\
\hline
\end{tabular}
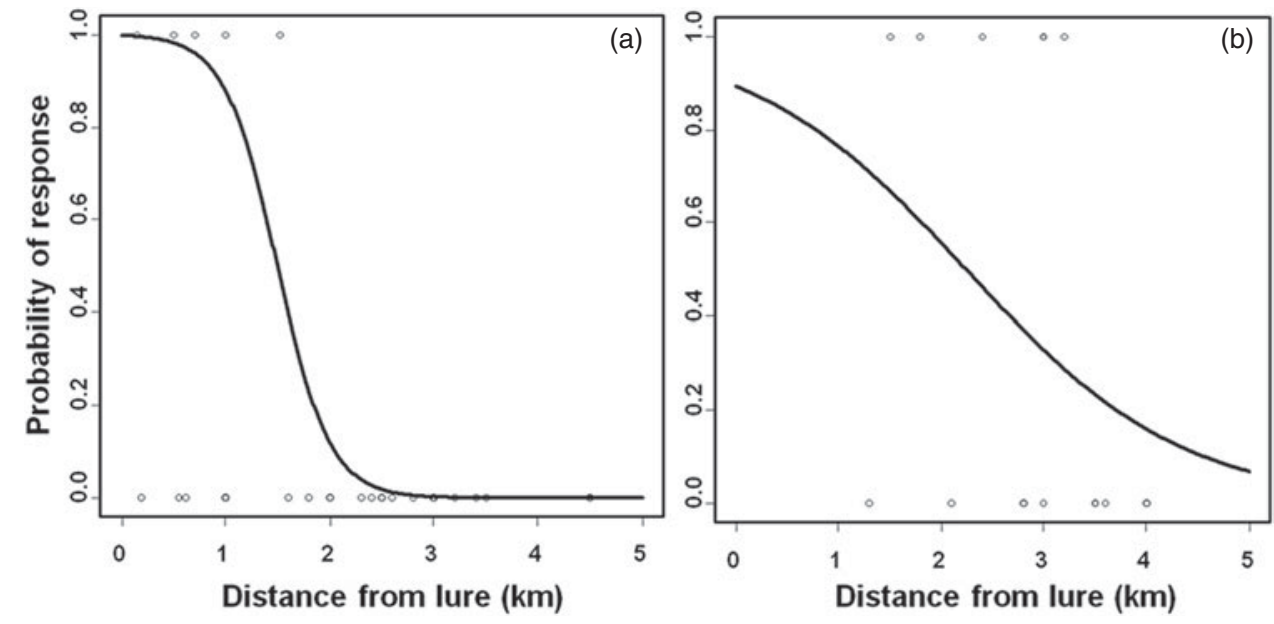

FIG. 2 The probability of response for lions (a), generated from data collected in this study, and for spotted hyaenas (b), from Mills (2001), plotted against distance $(\mathrm{km})$ from the call-up station. The curve represents animals that have not been involved in previous trials; probability of response is lower for animals that have been involved in previous trials. selected areas. On the roof rack, c. $2.5 \mathrm{~m}$ above the ground, we mounted an $\mathrm{FX}_{3}$ Snow Crow Pro call box attached to two 50-W SP108 deluxe cone speakers connected in series, powered by the car battery. A buffalo calf distress call was played repeatedly at maximum volume for 30 minutes at each call station in each of the study areas. After the first 15 minutes the speakers were rotated through $90^{\circ}$ to obtain a circular calling radius without any broadcast interruptions. On five occasions elephants approached within $50 \mathrm{~m}$; we stopped the playback and continued after they had left, to complete the 30 minutes of broadcast.

Observers sat quietly on the roof of the field car to observe the animals that responded to the call. With the car lights turned off, we scanned the area with a 350,000 candela spotlight with a red light filter attached. All animals that came to the call station were recorded, with their time of arrival. Carnivore sex and age classes were noted and we guarded against double counting individuals at each call station by tracking them carefully with the light until they left.

\section{Response curves of lions and hyaenas}

Call-up surveys require calibration experiments to determine the effective response distance and the variation of the response with distance from the call station (Buckland et al.,
2006). To calibrate the responses we conducted an experiment on known individual lions in the Queen Elizabeth Protected Area to establish the probability of response to the buffalo calf distress call at different distances from the speakers. Lion groups or individuals were located and a vehicle was parked some distance away to avoid influencing the lions' movements. The buffalo distress call was broadcast from a second car, $0.5-5 \mathrm{~km}$ away (calculated using a geographical positioning system). The selected individuals were observed and their response to the call and arrival at the vehicle with the call box system within 30 minutes was recorded. We used the binary data on whether or not lions responded to the playback and arrived at the vehicle, to fit a logistic regression, with initial distance from the speaker as a covariate, giving an estimated response curve. We found that individual lions were less likely to respond if exposed to subsequent calls in additional trials; therefore we added the number of repeats as a covariate in the logistic regression model for the response curve. The effective area surveyed around the speaker was estimated from the fitted response curve (Buckland et al., 2006). To calculate a similar response curve for hyaenas we used call response data from Kruger National Park (Mills, Juritz \& Zucchini, 2001). The response of hyaenas may vary between sites because of differences in vegetation and call-up equipment but it was not possible to calibrate the responses of hyaenas in Uganda because they were too wary of vehicles. 


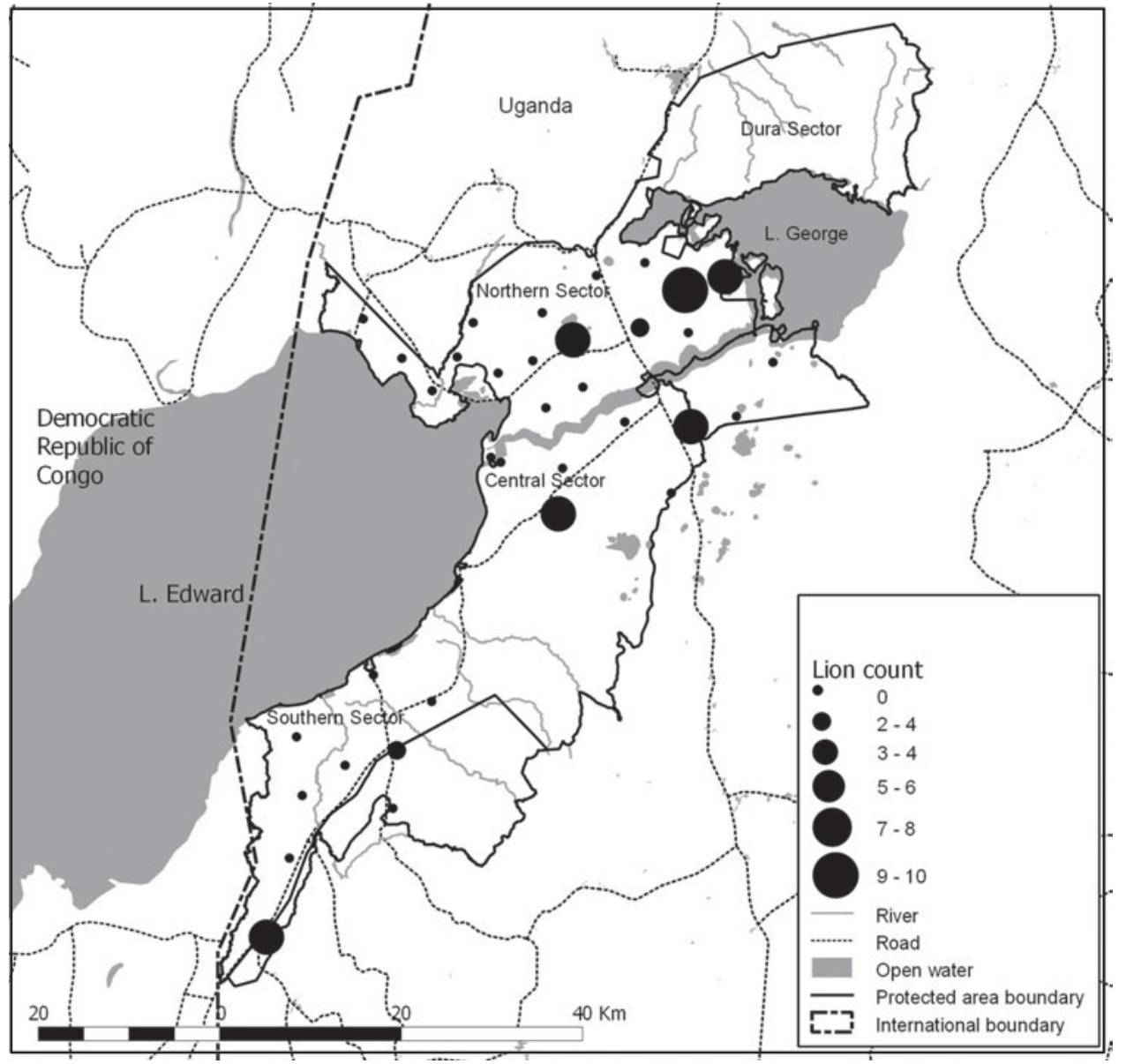

FIG. 3 The locations of call-up points and sites where lions responded in the Queen Elizabeth Protected Area.
TABLE 2 Estimated number ( \pm SE) of lions Panthera leo and hyaenas Crocuta crocuta in the three sectors of the Queen Elizabeth Protected Area, and overall, and north and south of the Nile in the Murchison Falls Conservation Area, and overall.

\begin{tabular}{lrc}
\hline & \multicolumn{1}{c}{ Lion } & Hyaena \\
\hline Queen Elizabeth Protected Area & & \\
North & $72 \pm 49$ & $64 \pm 30$ \\
Central & $41 \pm 30$ & $98 \pm 52$ \\
South & $27 \pm 25$ & $62 \pm 37$ \\
Total & $144 \pm 22$ & $211 \pm 25$ \\
Murchison Falls Conservation Area & & \\
North bank & $83 \pm 41$ & $12 \pm 7$ \\
South bank & $27 \pm 12$ & $29 \pm 12$ \\
Total & $132 \pm 24$ & $38 \pm 7$ \\
\hline
\end{tabular}

\section{Results}

A total area of $6,674 \mathrm{~km}^{2}$ was surveyed, with 35 playback points in the Queen Elizabeth Protected Area, 24 in Kidepo Valley National Park and 72 in Murchison Falls Conservation Area (Table 1). Hyaenas and lions responded differently to playbacks of the buffalo call (Fig. 2). The probabilities of detection of a lion and a hyaena within $5 \mathrm{~km}$ were 0.10 and 0.30 , respectively. The effective radius of response was calculated as $1.56 \mathrm{~km}$ for lions and $2.75 \mathrm{~km}$ for hyaenas, which is much lower than the maximum response distances ( 3.0 and $3.2 \mathrm{~km}$, respectively). This was used to calculate the area sampled and the percentage sampling effort for the conservation area (Table 1).

The buffalo calf distress call attracted both small and large carnivores to the call stations. Side-striped jackals Canis adustus, black-backed jackals Canis mesomelas, white-tailed mongooses Ichnuemia albicauda and large spotted genets Genetta tigrina responded in Kidepo Valley National Park and Murchison Falls Conservation Area. A total of 66 lions, 176 hyaenas and seven leopards were recorded at call stations. The Queen Elizabeth Protected Area had the largest single group response from lions (10, at a Ugandan kob Kobus kob thomasi lek in the northern sector; Fig. 3) and hyaenas (14, in the southern sector).

Using lure count analysis the Queen Elizabeth Protected Area was estimated to have a total of $144 \pm$ SE 22 lions. The number of hyaenas was estimated to be $211 \pm$ SE 25 . The Protected Area was divided into three sectors for analysis (Fig. 3; Table 2): northern (north of the Kazinga channel that runs between Lakes George and Edward), central (south of the Kazinga channel but north of Maramagambo forest) and southern (Ishasha sector). We have studied the lions in the southern sector since 2005 and recognize all of the 


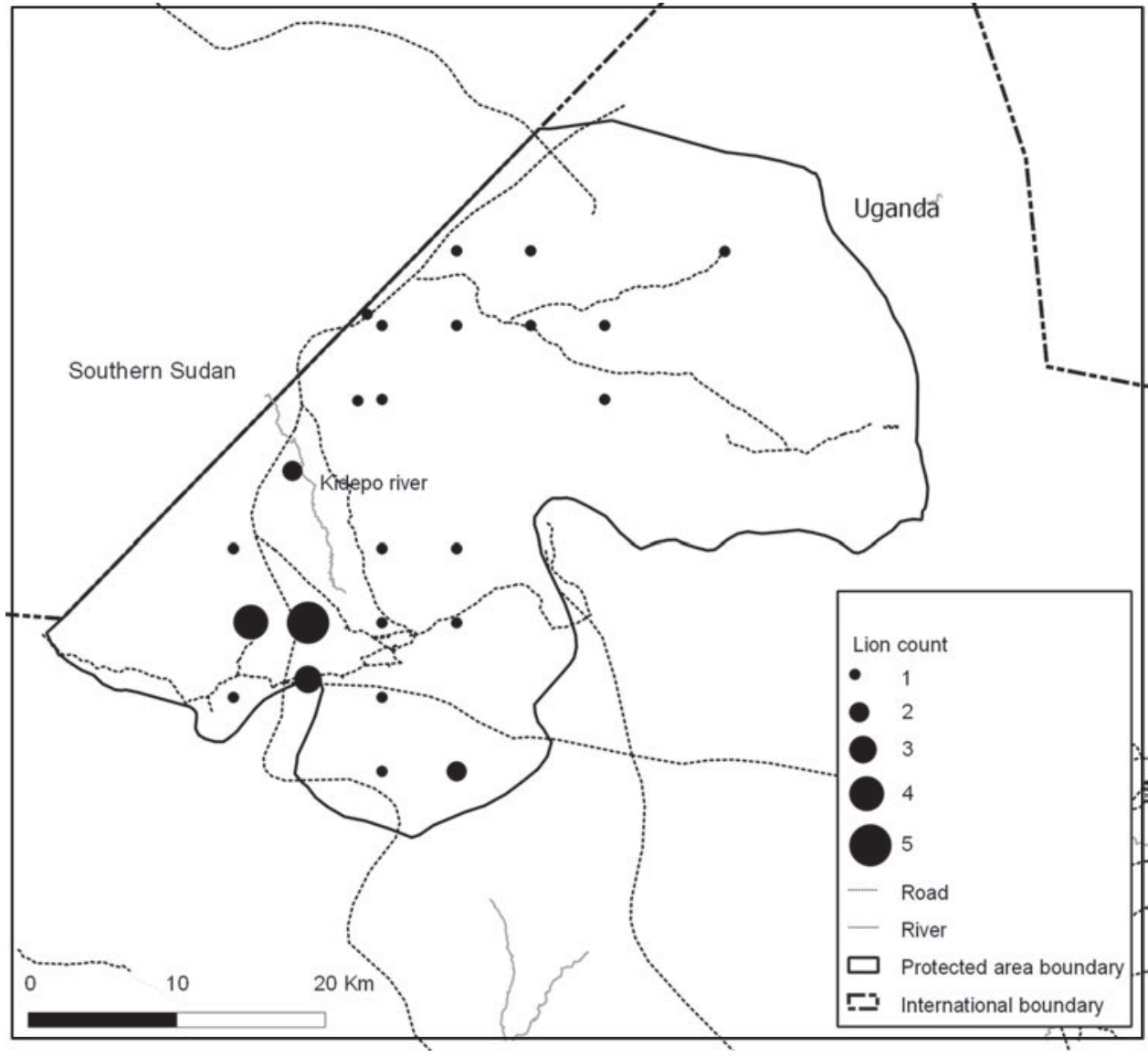

FIg. 4 The locations of call-up points and sites where lions responded in the Kidepo Valley National Park. individuals. The estimated abundance from the lure counts (27) was close to the known population at the time (29), providing some support for the use of this method to census lions. Standard errors of estimates are high because of small sample sizes.

Some areas in the east of Kidepo Valley National Park were omitted for reasons of security and poor accessibility but it is thought that few carnivores occur here because most of the prey species have been hunted by Karamojong warriors (Uganda Wildlife Authority, unpubl. aerial survey data). The largest group of lions (four individuals) in the Park (Fig. 4) was recorded in Narus valley, which constitutes the western half of the Park, and the largest hyaena group (eight individuals) was recorded in the same valley, near the Park headquarters. The estimated numbers of lions and hyaenas in the Park were $132 \pm$ SE 77 and $75 \pm$ SE 33, respectively.

In Murchison Falls Conservation Area the largest lion group recorded at a call station (four individuals) was at Pakuba Airstrip, in the north-west of the Park (Fig. 5). For analysis the Conservation Area was divided into the northern and southern banks of the Nile and estimates made for each bank (Table 2). Using the lure count analysis we estimated that there were $132 \pm$ SE 24 and $38 \pm$ SE 7 lions and hyaenas, respectively. The number of hyaenas is low given that this is the largest park in Uganda.
The three areas we surveyed contain most of Uganda's lions and hyaenas. There are very few lions (2-8) in the Toro-Semliki Wildlife Reserve and there have been sightings of up to five lions in Lake Mburo National Park after an absence of sightings for several years. Hyaenas are known to occur in Lake Mburo National Park, Mt Elgon National Park and Mgahinga Gorilla National Park but numbers are unknown and likely to be few (Uganda Wildlife Authority, unpubl. data). The wildlife reserves in the east of the country (Pian Upe, Matheniko and Bokora) may contain a small number of hyaenas but they have probably been hunted by Karamojong pastoralists and no sightings have been made by rangers in recent years. Therefore, our estimate of 408 lions and 324 hyaenas could probably be revised to a national population estimate by including a maximum of 10 lions at other sites and possibly 40 hyaenas, giving a total of c. 420 lions and 360 hyaenas in Uganda.

\section{Discussion}

In 2006 the Uganda Wildlife Authority (UWA), the Wildlife Conservation Society (WCS) and the Institut Congolais pour la Conservation de la Nature conducted aerial surveys of large mammals, including lion prey species, in the Queen 
TABLE 3 Estimates from researchers and park rangers of lion numbers in Uganda's conservation areas from 1997 to 2010 . The numbers for 2000-2002 and 2004 are based on educated guesses; all other numbers are based on survey data.

\begin{tabular}{|c|c|c|c|c|c|c|c|}
\hline & $1997-1981$ & 1994-1996 & 1997-1999 & $2000-2002$ & 2004 & 2005 & 2010 \\
\hline Queen Elizabeth Protected Area & 400 & & 185 & $90-190$ & 200 & & 144 \\
\hline Murchison Falls Conservation Area & & & & $181-467$ & 350 & 263 & 132 \\
\hline Kidepo Valley National Park & & & & $35-60$ & 25 & & 132 \\
\hline Toro-Semliki Wildlife Reserve & & & & $5-15$ & & & \\
\hline Lake Mburo National Park & & 7 & & 2 & & & \\
\hline Source & $\begin{array}{l}\text { Din, 1978; } \\
\text { Van Orsdol, } \\
1981\end{array}$ & $\begin{array}{l}\text { UWA } \\
\text { unpubl. } \\
\text { data }\end{array}$ & $\begin{array}{l}\text { Driciru, } \\
1999\end{array}$ & $\begin{array}{l}\text { Driciru } \\
\text { et al., } \\
2005\end{array}$ & $\begin{array}{l}\text { Bauer \& } \\
\text { Van der } \\
\text { Merwe, } 2004\end{array}$ & $\begin{array}{l}\text { Driciru, } \\
2005\end{array}$ & $\begin{array}{l}\text { This } \\
\text { study }\end{array}$ \\
\hline
\end{tabular}

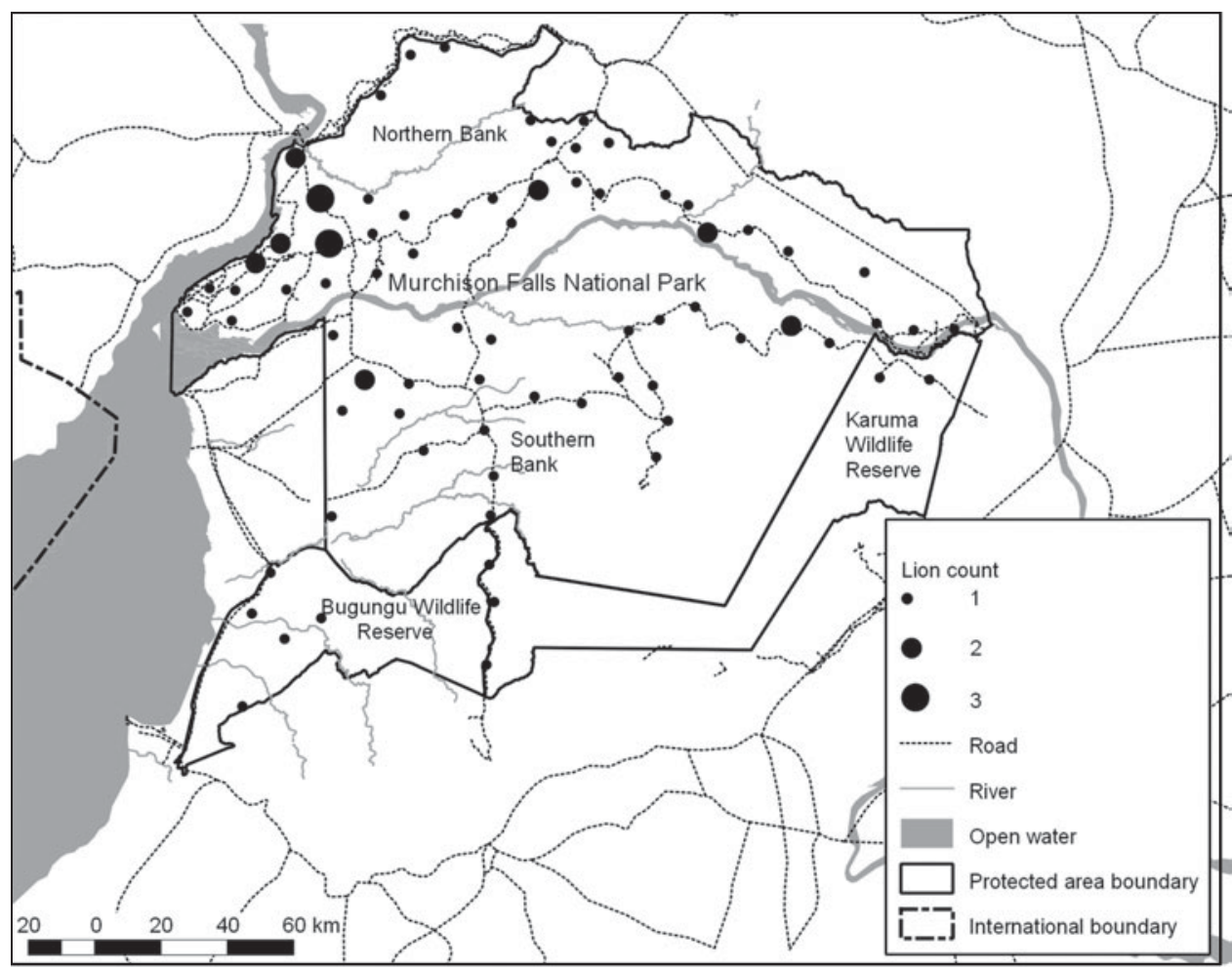

FIG. 5 The locations of call-up points and sites where lions responded in the Murchison Falls Conservation Area.
Elizabeth Protected Area and Parc National des Virunga in neighbouring Democratic Republic of the Congo. Prey species included buffalo Syncerus caffer, bushpig Potamochoerus larvatus, bushbuck Tragelaphus scriptus, Ugandan kob Kobus kob thomasi, warthog Phacochoerus africanus, waterbuck Kobus ellipsiprymnus, reedbuck Redunca redunca and topi Damaliscus lunatus. Treves et al. (2009) used these surveys to estimate the number of lions from prey densities. They estimated 140 lions in the Protected Area, which is close to our own estimate. These calculations indicate that the estimated population of lions is probably close to the carrying capacity of the Protected Area, based on prey availability.

In Murchison Falls Conservation Area and Kidepo Valley National Park aerial surveys of large mammals were conducted in 2010 by UWA and WCS. Prey species included giraffe Giraffa camelopardalis rothschildi, Ugandan kob, warthog, waterbuck, buffalo and hartebeest Alcelaphus buselaphus. Kidepo Valley National Park also contained bush duiker Sylvicapra grimmia, eland Taurotragus oryx, reedbuck, and zebra Equus quagga. Based on these prey estimates the number of lions in the Murchison Falls Conservation Area is estimated to be 171 , compared with $132 \pm$ SE 24 predicted by the lure count analysis. However, lions have been monitored on the northern bank of the Nile since 2010 and at least 79 individual lions are recognized, which is relatively close to the 83 estimated from prey abundance in that area. In total 40 lions responded to the call-ups in Kidepo Valley National Park. There is a large standard error around the estimate of $132 \pm 77$ for this population because lions only responded at five call-up points (Fig. 4). Based on rangers' knowledge of the lions in the Park we believe we 
may be overestimating the number of lions here. We recommend a more intensive survey of the Narus valley, with more call-up points, to generate a better estimate of the populations of lions and hyaenas in this Park.

Studies of the lion in Uganda have been neither consistent nor exhaustive. The Queen Elizabeth Protected Area has been surveyed most frequently (Din, 1978; van Orsdol, 1981; Driciru, 1999). Although previous researchers have used a different survey method we believe that the results we obtained using the call-up method are at approximately the correct level. The trends in the estimates show that lion numbers have been decreasing in the Queen Elizabeth Protected Area and Murchison Falls National Park but increasing in Kidepo Valley National Park (Table 3).

Lion numbers declined by nearly $3 \%$ per year during 1999-2009 in the Queen Elizabeth Protected Area, if previous estimates are comparable with our numbers.

There are no published data on hyaena population status in Uganda and it is therefore difficult to assess the trend in hyaena numbers. However, we know that hyaenas have been killed by poisoning in retaliation for killing livestock. The carcasses of cattle that have been killed by predators are laced with Carbofuran or a similar insecticide and this kills whatever species feeds on the carcass, including hyaenas, lions and vultures (Okot \& Plumptre, 2011). It is probable that hyaenas are also declining as a result of poisoning. The use of calibration data from Kruger National Park may have affected the population estimates as a result of variations in vegetation, call-up equipment and temperature, all of which may lead to different responses by hyaenas. Developing a calibration curve for this species in Uganda should be a priority for future research.

Our survey results have been used by the Uganda Wildlife Authority to help develop a conservation action plan for Uganda's large carnivores (UWA, 2010). The plan aims to tackle some of the main threats to carnivores, particularly human-wildlife conflict over livestock losses, road kills in protected areas, and killing of carnivores for trade in body parts. It also supports initiatives to improve prey numbers. The lure count analysis method from call-up counts described here will be used to monitor the numbers of lions and hyaenas to assess whether the decline in numbers has been halted or reversed.

\section{Acknowledgements}

We are grateful to Panthera and the United States Agency for International Development for the training and donation provided to make this research possible. We also thank the Uganda Wildlife Authority for granting us permission to conduct our study in National Parks, with the assistance of armed rangers, and Mustafa Nsubuga for assistance with field data collection.

\section{References}

Bauer, H. \& VAn Der Merwe, S. (2004) Inventory of free-ranging lions Panthera leo in Africa. Oryx, 38, 26-31.

Buckland, S.T., Summers, R.W., Borchers, D.L. \& Thomas, L. (2006) Point transect sampling with traps or lures. Journal of Applied Ecology, 43, 377-384.

Dacier, A., Gabriela de Luna, A., Fernandez-Duque, E. \& Di Fiore, A. (2011) Estimating population density of Amazonian Titi Monkeys (Callicebus discolor) via playback point counts. Biotropica, 43, 135-140.

Din, N.A. (1978) Notes on two lion prides near Mweya in the Ruwenzori National Park, Uganda. Pakistan Journal of Zoology, 10, 133-138.

Driciru, M. (1999) Lions of Queen Elizabeth, their population and health status. Unpublished report. Makerere University, Kampala, Uganda.

Driciru, M. (2005) Predictive population viability of lions in Murchison Falls National Park. MSc thesis. Makerere University, Kampala, Uganda.

Driciru, M., Siefert, L. \& Mapesa, M. (2005) Status of lions in Uganda. Unpublished report to Uganda Wildlife Authority.

Ferreira, S.M. \& Funston, P.J. (2010) Estimating lion population variables: prey and disease effects in Kruger National Park, South Africa. Wildlife Research, 37, 194-206.

Hayward, M.W. \& Kerley, G.I.H. (2005) Prey preferences of the lion (Panthera leo). Journal of Zoology, 267, 309-322.

HunTER, L.T.B. (1998) Early post-release movements and behaviour of reintroduced cheetahs and lions, and technical considerations in large carnivore restoration. In Proceedings of a Symposium on Cheetahs as Game Ranch Animals (ed. B.L. Penzhorn), pp. 72-82. S.A. Veterinary Association, Onderstepoort, South Africa.

IUCN (2007) Regional Conservation Strategy for the Lion Panthera Leo in Eastern and Southern Africa. IUCN Cat Specialist Group, Gland, Switzerland.

Kiffner, C., Meyer, B., Michael, M. \& Waltert, M. (2009) Plenty of prey, few predators: what limits lions Panthera leo in Katavi National Park, western Tanzania? Oryx, 43, 52-59.

Mills, M.G.L. (1985) Hyaena survey of Kruger National Park, August-October, 1984. IUCN/SSC Hyena Specialist Group Newsletter, 2, 15-25.

Mills, M.G.L. \& Hofer, H. (1998) Hyaenas: Status Survey and Conservation Action Plan. IUCN/SSC Hyaena Specialist Group, Gland, Switzerland, and Cambridge, UK.

Mills, M.G.L., Juritz, J.M. \& Zucchini, W. (2001) Estimating the size of spotted hyaena (Crocuta crocuta) populations through playback recordings allowing for non-response. Animal Conservation, 4, 335-343.

Ogutu, J.O. \& Dublin, H.T. (1998) The response of lions and spotted hyenas to sound playbacks as a technique for estimating population size. African Journal of Ecology, 36, 83-95.

Окот, E.O. \& Plumptre, A.J. (2011) An assessment of availability and use of Carbofuran and other agro-vet chemicals used to poison lions, around Queen Elizabeth Conservation Area (QECA) and in Kampala, Uganda. Unpublished report to Panthera. Http://www. albertinerift.org/AboutUs/Publications.aspx [accessed 6 September 2013].

Schaller, G.B. (1972) The Serengeti Lion. A Study of Predator-Prey Relations. University of Chicago Press, Chicago, USA. 
Treves, A., Plumptre, A.J., Hunter, L. \& Ziwa, J. (2009) Identifying a potential lion, Panthera leo, stronghold in Queen Elizabeth National Park, Uganda and Parc National des Virunga, Democratic Republic of Congo. Oryx, 43, 1-8.

UWA (Uganda Wildlife Authority) (2010) Strategic action plan for large carnivore conservation in Uganda. Unpublished report. Http://www.albertinerift.org/AboutUs/ Publications.aspx

VAn Orsdol, K.G. (1981) Lion predation in Rwenzori National Park, Uganda. PhD thesis. University of Cambridge, Cambridge, UK.

Whitman, K.L., Durant, S.M., Maddox, T.M., Laake, J.L. \& PACKer, C. (2006) The limitations of using spotted hyaena call-ins to esetimate lion population size. In Modelling, monitoring and the sustainable use of lion populations in Tanzania (ed. K.L. Whitman). PhD thesis. University of Minnesota, St Paul, USA.

\section{Biographical sketches}

EDWARD Окот Омоча has been studying and conserving the lion population of Queen Elizabeth Protected Area, focusing on the population dynamics of the tree-climbing lions of Ishasha and working with the Basongora pastoralists to tackle human-wildlife conflict. Tutilo Mudumba has been studying and conserving the lion population in Murchison Falls National Park. His research focuses on the impacts of oil exploration on large carnivores and their prey. STEPHEN BUCKLAND's research interests include modelling population dynamics, wildlife resource management, wildlife population assessment, distance sampling and biodiversity monitoring. PAUL MULONDO is studying the effects of oil exploration on large mammals and birds in the Murchison Falls National Park. Andrew Plumptre has been undertaking applied conservation research in east Africa since 1988. His research interests include survey methods in tropical forests, conservation planning and conservation of great apes. 